\title{
Inhibition of Intestinal Epithelial Wound Healing through Protease-Activated Receptor-2 Activation in Caco2 Cells ${ }^{\mathrm{s}}$
}

\author{
Elizabeth H. Fernando, Marilyn H. Gordon, Paul L. Beck, and Wallace K. MacNaughton \\ Departments of Physiology and Pharmacology (E.H.F., M.H.G., W.K.M.) and Medicine (P.L.B.), Cumming School of Medicine, \\ University of Calgary, Calgary, Alberta, Canada
}

Received March 29, 2018; accepted August 31, 2018

\begin{abstract}
The mechanisms of epithelial wound healing are not completely understood, especially in the context of proteases and their receptors. It was recently shown that activation of proteaseactivated receptor-2 (PAR2) on intestinal epithelial cells induced the expression of cyclooxygenase-2 (COX-2), which has protective functions in the gastrointestinal tract. It was hypothesized that PAR2-induced COX-2 could enhance wound healing in intestinal epithelial cells. Caco2 cells were used to model epithelial wound healing of circular wounds. Cellular proliferation was studied with a 5-ethynyl-2'-deoxyuridine assay, and migration was studied during wound healing in the absence of proliferation. Immunofluorescence was used to visualize E-cadherin and F-actin, and the cellular transcription profile during wound healing and PAR2 activation was explored with
\end{abstract}

RNA sequencing. PAR2 activation inhibited Caco2 wound healing by reducing cell migration, independently of COX-2 activity. Interestingly, even though migration was reduced, proliferation was increased. When the actin dynamics and cell-cell junctions were investigated, PAR2 activation was found to induce actin cabling and prevent the internalization of E-cadherin. To further investigate the effect of PAR2 on transcriptionally dependent wound healing, RNA sequencing was performed. This analysis revealed that PAR2 activation, in the absence of wounding, induced a similar transcriptional profile compared with wounding alone. These findings represent a novel effect of PAR2 activation on the mechanisms of epithelial cell wound healing that could influence the resolution of intestinal inflammation.

\section{Introduction}

The intestinal epithelial barrier can be damaged by a variety of external and host-derived factors, resulting in ulceration. If a compromised intestinal epithelial barrier cannot be healed, chronic inflammation will develop due to the constant inflammatory stimuli crossing the damaged mucosal barrier (Pastorelli et al., 2013). Loss of epithelial barrier function is characteristic of gastrointestinal diseases such as inflammatory bowel disease (IBD). Two main forms of IBD, Crohn's disease and ulcerative colitis, are relapsing/ remitting inflammatory conditions having an increasing prevalence worldwide, but particularly in industrialized countries (Kaplan and $\mathrm{Ng}$, 2017). The primary goal of IBD treatment is mucosal healing since it is the strongest predictor

Portions of this work were included in Dr. Elizabeth Fernando's Ph.D. dissertation, entitled "The Role of Protease-Activated Receptor-2 during Wound Healing in Intestinal Epithelial Cells" located at the University of Calgary Digital Collections (https://prism.ucalgary.ca/handle/11023/3558).

This work was supported by a grant-in-aid to W.K.M. and P.L.B. from Crohn's and Colitis Canada. E.H.F. was the recipient of a studentship from the Alberta Cancer Board. The support of the Live Cell Imaging Facility within the Snyder Institute for Chronic Diseases at the University of Calgary is gratefully acknowledged.

https://doi.org/10.1124/jpet.118.249524.

S This article has supplemental material available at jpet.aspetjournals.org. of sustained clinical remission and reduced rates of hospitalization and surgery (Pineton de Chambrun et al., 2016). Re-establishment of epithelial homeostasis is a key element in mucosal healing, although the mechanisms involved are not fully understood.

It has long been known that epithelial cells at the edge of a damaged area will lose their columnar polarity to flatten and cover more surface area while migrating into the denuded area (Lacy, 1988). This process of epithelial restitution involves cell migration that is in large part mediated by the Rho family guanosine triphosphatases (GTPases) that organize and remodel the actin cytoskeleton through the formation of stress fibers, lamellipodia, and filopodia. There is also a requirement for epithelial cells to modulate the cell-cell junctions to allow for migration (Huang et al., 2012). Additionally, epithelial cells will proliferate to increase the number of cells available to cover the wound, and then differentiate into mature columnar epithelial cells restoring the original phenotype of the epithelium.

There are numerous factors that mediate intestinal epithelial wound healing through either increased migration or proliferation, including growth factors, cytokines, and peptides (Iizuka and Konno, 2011; Kuhn et al., 2014). Transforming growth factor- $\beta$ is considered the central factor of

ABBREVIATIONS: COX-2, cyclooxygenase-2; DAPI, 4',6-diamidine-2-phenylindole; DMSO, dimethylsulfoxide; EdU, 5-ethynyl-2'-deoxyuridine; EGF, epidermal growth factor; FBS, fetal bovine serum; 2fLI, 2-furoyl-LIGRLO- $\mathrm{NH}_{2}$; 2fO, 2-furoyl-OLRGIL-NH ${ }_{2}$; IBD, inflammatory bowel disease; MMC, mitomycin C; NW-Con, nonwounded control; NW-PAR2, nonwounded with protease-activated receptor-2 activation; PAR2, proteaseactivated receptor-2; W-Con, wounded control; W-PAR2, wounded with protease-activated receptor-2 activation. 
wound healing (Beck et al., 2003). Importantly, it was recently shown in pancreatic cells that transforming growth factor$\beta$-induced migration requires the presence of proteaseactivated receptor-2 (PAR2) (Zeeh et al., 2016). PAR2 is a G protein-coupled receptor that is activated by cleavage of the extracellular $\mathrm{N}$-terminus, which reveals a new sequence that acts as a tethered ligand to activate the receptor. PAR2 has been associated with IBD since levels of mast cell tryptase, an endogenous activator of PAR2, were found to be increased in Crohn's disease and ulcerative colitis (Raithel et al., 2001), and the expression of PAR2 was increased in intestinal epithelial cells in canine IBD (Maeda et al., 2014). Importantly, PAR2 activation increases migration and proliferation in many tissues, including the colon (Darmoul et al., 2004; Zhou et al., 2011), pancreas (Shi et al., 2013), prostate (Mize et al., 2008), and breast (Ge et al., 2004; Morris et al., 2006), which could also contribute to PAR2-mediated enhanced wound healing.

The mechanism by which PAR2 induces epithelial cell migration is not known but may be related to changes in gene expression following PAR2 activation. PAR2-induced upregulation of cyclooxygenase-2 (COX-2) was first demonstrated in endothelial cells (Houliston et al., 2002), then in airway epithelial cells (Kawao et al., 2005), and more recently in intestinal epithelial cells (Hirota et al., 2012). However, the effects of PAR2-induced COX-2 expression on intestinal epithelial wound healing are unknown. COX-2 and COX-2derived lipid mediators have been associated with active IBD for decades (Shafran et al., 1977; Singer et al., 1998); however, it is now recognized that COX-2-derived prostanoids have important roles in mucosal protection and the resolution of intestinal inflammation (Ajuebor et al., 2000; Wallace and Devchand, 2005). With respect to wound healing, mice deficient in COX-2 are unable to heal biopsy-induced intestinal wounds (Manieri et al., 2012). In gastric mucosal lesions, COX-2 expression is increased early and most strongly at the edges of ulcerated regions, and the inhibition of COX-2 can delay ulcer healing (Mizuno et al., 1997; Schmassmann et al., 1998; Halter et al., 2001). In regard to COX-2-derived lipid mediators, prostaglandin $\mathrm{E}_{2}$ has been shown to enhance wound closure in both airway epithelial cells (Savla et al., 2001) and intestinal epithelial cells (Miyoshi et al., 2017), which may be due to increased migration ( $\mathrm{Li}$ et al., 2015).

The purpose of this study was to investigate the mechanisms of intestinal epithelial wound healing, specifically in the context of proteases and their receptors, and how these mechanisms may relate to COX-2 expression and activity. We hypothesized that PAR2 activation in intestinal epithelial cells would drive a prowound healing response through the effects of COX-2-derived lipid mediators.

\section{Materials and Methods}

\section{Cell Culture}

Caco2 cells (human epithelial colorectal adenocarcinoma), originally from ATCC (Manassas, VA), were kindly provided by Dr. Simon Hirota (University of Calgary). This cell line is commonly used in studies of intestinal epithelial wound healing (Charrier et al., 2005). All experiments were performed with cells from passages 56 to 80 . Caco-2 media consisted of DME/F12 (SH30023.01; HyClone, Chicago, IL) supplemented with $10 \%$ fetal bovine serum (FBS) (12483-020; Gibco ThermoFisher, Waltham, MA), $100 \mathrm{IU} / \mathrm{ml}$ penicillin-100 $\mu \mathrm{g} / \mathrm{ml}$ streptomycin (SV30010; HyClone), and a low, maintenance dose of plasmocin ( $5 \mu \mathrm{g} / \mathrm{ml}$; InvivoGen, San Diego, CA). Cells were cultured at $37^{\circ} \mathrm{C}$ in $5 \% \mathrm{CO}_{2}$, fed every 2 days with prewarmed media, and subcultured every 4 to 5 days using trypsin-EDTA (T4174, SigmaAldrich, Oakville, Ontario, Canada).

\section{PAR2 Receptor Activation}

PAR2 was activated using 2-furoyl-LIGRLO-NH ${ }_{2}$ (2fLI), a small PAR2-selective peptide with sequence similarity to the endogenous postcleavage tethered ligand (McGuire et al., 2004). The inactive reverse sequence peptide 2-furoyl-OLRGIL- $\mathrm{NH}_{2}(2 \mathrm{fO})$ was used as a control (Hollenberg et al., 2008). Peptides were kindly provided by Dr. M. Hollenberg (University of Calgary).

\section{Circular Wound Healing}

Wounding was performed with a pipette tip attached to the end of an aspirator. Caco2 cells were plated and analyzed under a variety of conditions. For standard wound healing experiments, Caco2 cells $(8 \times$ $10^{4}$ cells/well) were plated in a 12-well dish and grown for 3 days to confluence; for postconfluent wound healing, Caco2 cells $\left(8 \times 10^{4}\right.$ cells/well) were plated in a 12 -well plate and grown for 21 days to induce differentiation. When using Transwell filter supports, to ensure polarization of the Caco 2 cells, $1 \times 10^{5}$ cells/insert were plated on Transwell supports (3460; Corning, Corning, NY) and grown for 5 days. Cells were then serum starved overnight, and wounded the following morning. Images of each wound were captured every 12 hours (beginning at 0 hour) with an AxioCam MRc camera on an AxioVert25 microscope using AxioVision Rel 4.6 software (Zeiss, Oberkochen, Germany). Wounds were manually traced using (ImageJ, NIH, Bethesda, MD) software, and the percentage of initial wound area was calculated. In live-cell experiments, Caco2 cells $(8 \times$ $10^{4}$ cells/well) were plated in a 12 -well dish and grown for 3 days to confluence. Following overnight serum starvation, cells were wounded and treated with peptides at 0 hour before being transported to a prewarmed live-cell chamber where cells were maintained at $37^{\circ} \mathrm{C}$ with $5 \% \mathrm{CO}_{2}$ on an Olympus IX71 inverted microscope equipped with a ProscanIII motorized stage (Olympus Canada, Markham, Ontario, Canada) and a Hamamatsu OrcaR2 cooled charge-coupled device 12-bit camera (Hamamatsu Corp, Bridgewater, NJ). Using Volocity Acquisition software (Quorum Technologies, Puslinch, Ontario, Canada) and point visiting, which saved the $x, y$, and $z$ coordinates that were manually set for each wound, the wounds were imaged every 15 minutes for 24 hours. With the MTrackJ plugin in FIJI, individual cells around the perimeter of the wound were tracked and the total distance traveled by each cell was recorded. For staining experiments,

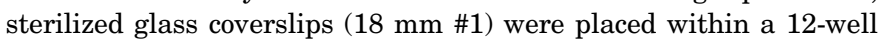
plate, and Caco 2 cells $\left(9 \times 10^{4}\right.$ cells/well $)$ were grown for 3 days. Cells were starved overnight, wounded on day 4 , and used at two time points: cells were either treated with peptides at 0 hour and fixed at 12 hours or treated with peptides at 0 and 12 hours and fixed at 24 hours. These cells were used for both 5-ethynyl-2'-deoxyuridine (EdU) and immunofluorescence staining. Growth factors and pharmacological inhibitors were used in certain wound healing experiments. Epidermal growth factor (EGF) (GF-010-8; Cedarlane, Burlington, Ontario, Canada) was added at 0 and 24 hours (5 and $20 \mathrm{ng} / \mathrm{ml}$ ). The selective COX-2 inhibitor NS-398 (70590 Cayman) was added to cells at 0 and 24 hours ( $10 \mu \mathrm{g} / \mathrm{ml})$, and an equivalent volume of dimethylsulfoxide (DMSO) (1:2000) was added at the same time points as the vehicle control. Actinomycin D (A1410; Sigma), used to inhibit transcription, was added to the cells at 0 hour $(5 \mu \mathrm{g} / \mathrm{ml})$, and an equivalent volume of DMSO (1:200) was used as the vehicle control. To inhibit proliferation, cells were pretreated with the irreversible inhibitor mitomycin C (MMC) (5 $\mu \mathrm{g} / \mathrm{ml}$; sc3517; Santa Cruz, Dallas, TX) for 2 hours, washed with phosphate-buffered saline, and then wounded. As a vehicle control, an equivalent volume of DMSO (1:750) was used to pretreat the cells. 


\section{EdU Proliferation}

To assess proliferation in confluent and wound-edge cells, the Click-iT EdU AlexaFluor488 Imaging Kit (C10337; Life Technologies, Burlington, Ontario, Canada) was used according to the manufacturer's protocol. Briefly, $50 \%$ of the media was replaced with fresh media containing $20 \mu \mathrm{M}$ EdU (final concentration $10 \mu \mathrm{M}$ EdU) and cells were returned to the incubator for 2 hours. Coverslips were fixed with 4\% paraformaldehyde (43368; Alfa Aesar, Ward Hill, MA) for 15 minutes, permeabilized with $0.5 \%$ Triton-X for 20 minutes, incubated with Click-iT reaction cocktail for 30 minutes, and then incubated with 4',6-diamidine-2-phenylindole (DAPI) for 30 minutes (1:50000, D1306; Invitrogen Calsbad, Ca). Coverslips were mounted with FluorSave (34789; Calbiochem, Darmstadt, Germany). Widefield $(10 \times)$ images were captured with an Olympus IX71 inverted microscope equipped with a Hamamatsu OrcaR2 12-bit camera. Using ImageJ software, cells were counted separately in DAPI and EdU images, and data were expressed as percentage of EdU-positive cells.

\section{Immunofluorescence Staining}

Either 12 or 24 hours after wounding Caco 2 cells on glass coverslips, cells were fixed in $4 \%$ paraformaldehyde for 15 minutes. Cells were blocked and permeabilized in $10 \% \mathrm{w} / \mathrm{v}$ bovine serum albumin/ phosphate-buffered saline containing $0.1 \%$ Triton-X for 1 hour at room temperature on a rocking platform. Anti-E-cadherin antibody (1: 200, BD Biosciences Mississauga, Ontario, Canada) or anti-PAR2 antibody (1:100, A5, supplied by Dr. M. Hollenberg, University of Calgary) was added to the well and the coverslips were incubated at $4^{\circ} \mathrm{C}$ overnight on a rocking platform. The following day, the subsequent steps were performed, separated by a single wash step at room temperature and protected from light on a rocking platform: incubation with secondary antibody for 2 hours (1:200, A11031; Invitrogen), incubation with phalloidin- 488 for 30 minutes (1:1000, A12379; Invitrogen), and finally incubation with DAPI for 30 minutes. Coverslips were mounted with FluorSave. Wide-field images $(20 \times)$ were captured with a Leica DMi6000 B inverted microscope equipped with a fully motorized XY stage and piezo Z stage insert Leica Canada, Concord, Ontario, Canada, or a Nikon Ti Eclipse Widefield Microscope Nikon Instruments, Melville, NY. MetaMorph software (Molecular Devices, San Jose, CA) with a slide-scan function was used during acquisition to stitch the $20 \times$ images together to visualize the entire wound.

Quantification of Actin and E-Cadherin Loss. Four blinded researchers were provided with images that were used to quantify the actin properties and the loss of E-cadherin from the edge of the wound. This was done using ImageJ to manually trace both the length of the actin cable and lamellipodia at the perimeter of the wound, as well as the area surrounding the wound where E-cadherin was not apparent in the intercellular junctions. These values were normalized with the total perimeter length of the respective wound. The average was calculated from the values provided by the four researchers, and are reported here.

\section{RNA Sequencing}

Caco-2 cells $\left(2 \times 10^{5}\right.$ cells/well $)$ were grown to confluence in six-well plates, starved overnight, and then used to create four conditions: nonwounded control (NW-Con), wounded control (W-Con), nonwounded with PAR2 activation (NW-PAR2), and wounded with PAR2 activation [(W-PAR2); $10 \mu \mathrm{M}$ of $2 \mathrm{fLI}]$. Wounding was performed using a pipette tip attached to the end of an aspirator to create a grid pattern (10 vertical, 10 horizontal, and five across each diagonal) in order to maximize the number of wounded/migrating cells. Three hours after wounding, RNA was isolated using the RNeasy kit (74106; Qiagen, Valencia, CA) according to the manufacturer's instructions. The isolated RNA from biologic triplicates of each condition, collected from independent experiments performed on different days, was submitted for processing to the Alberta Children's Hospital Research Institute Genomics and Informatics Facility (Calgary, Alberta, Canada). The quality of each sample was verified via NanoDrop
ThermoFisher, Waltham, MA, Qubit Invitrogen, Carlsbad, CA, and TapeStation (Agilent, Santa Clara, CA). Total RNA samples were then prepared into libraries using an Illumina TruSeq Stranded mRNA sample preparation kit (Illumina, San Diego, CA). The indexed libraries were quantified with KAPA qPCR (Roche Canada, Mississauga, Ontario, Canada), normalized, and pooled for sequencing. Sequencing was performed on an Illumina NextSeq500 with a highoutput version 2 sequencing kit ( 75 cycles, single end). After sequencing, run metrics were verified and the data were uploaded to the Galaxy server (https://usegalaxy.org/). Raw NextSeq BCL files were converted to FASTQ format using bcl2fastq version 2.15.0.4 (Illumina). To analyze the data with the web interface of Galaxy, FASTQ files were mapped to the hg19(GRCh37) reference genome using TopHat version 2.1.0 (Center for Computational Biology, Johns Hopkins University, Baltimore, MD) with the UCSC Known Genes (https://genome.ucsc.edu/) track as a splice site guide, and underlying Bowtie version 2.2.6 (SourceForge, https://sourceforge.net/) used in the fast mode. Multiple binary alignment map files across lanes and runs were merged using SAMtools version 0.1.9 SourceForge to produce one final binary alignment map file for each input biologic sample. Binary alignment map files were run with CuffDiff (http://software.broadinstitute.org/cancer/software/genepattern/modules/docs/Cuffdiff/7), and differential gene expression testing results were exported for further analysis of comparisons between NW-Con and each of the three other groups, W-Con, NW-PAR2, and W-PAR2. The Gene Ontology terms "Regulation of Response to Wounding [1903034]" and "Cell Migration [0016477]" were used with adjusted $P$ values of $<0.05$ to narrow down gene lists of interest, and fold changes were compared and visualized by creating heatmaps using Microsoft Excel.

\section{Statistics}

Data expressed as mean \pm S.E. were graphed and analyzed using GraphPad Prism 7.00 (GraphPad Software, La Jolla, CA). Student's $t$ test was used to compare two groups. One- and two-way analyses of variance were used when appropriate followed by Bonferroni's multiple comparisons test. A value of $P<0.05$ was considered significant.

\section{Results}

PAR2 Activation Inhibits Circular Wound Healing in Caco2 Cells. To test the hypothesis that PAR2 activation would enhance intestinal epithelial wound healing, the area of circular wounds was measured as they healed over 48 hours with and without exposure to the PAR2 activating peptide, $2 \mathrm{fLI}(10 \mu \mathrm{M})$. As expected, circular wounds healed significantly over 48 hours, under both serum (10\%) and no-serum conditions. Exposure of wounded Caco2 monolayers to $10 \%$ serum resulted in much greater wound healing than cells incubated without serum (Fig. 1, A and B). Contrary to our hypothesis, PAR2 activation significantly inhibited wound closure compared with control and reverse peptide-treated wounds (Fig. 1). To fully characterize this inhibitory response, wounds were analyzed as they healed in media containing full serum (10\%, Fig. 1A), and media containing low serum $(0.5 \%$, Fig. 1B). Additionally, when the cells were both polarized on Transwell supports, or differentiated by culturing for 21 days, PAR2 activation was still able to inhibit wound healing (Fig. 1, $\mathrm{C}$ and D). As a positive control, cells were treated with EGF (5 and $20 \mathrm{ng} / \mathrm{ml}$ ), which significantly enhanced wound healing compared with control (Fig. 1E). Therefore, although wounded Caco-2 monolayers are capable of responding to $10 \%$ serum and EGF with enhanced wound healing, activation of PAR2 had the opposite effect, and significantly slowed healing of circular wounds. 
A

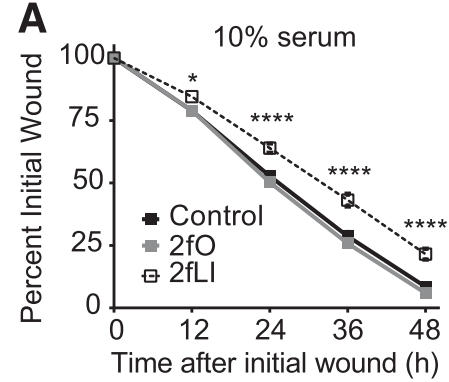

B
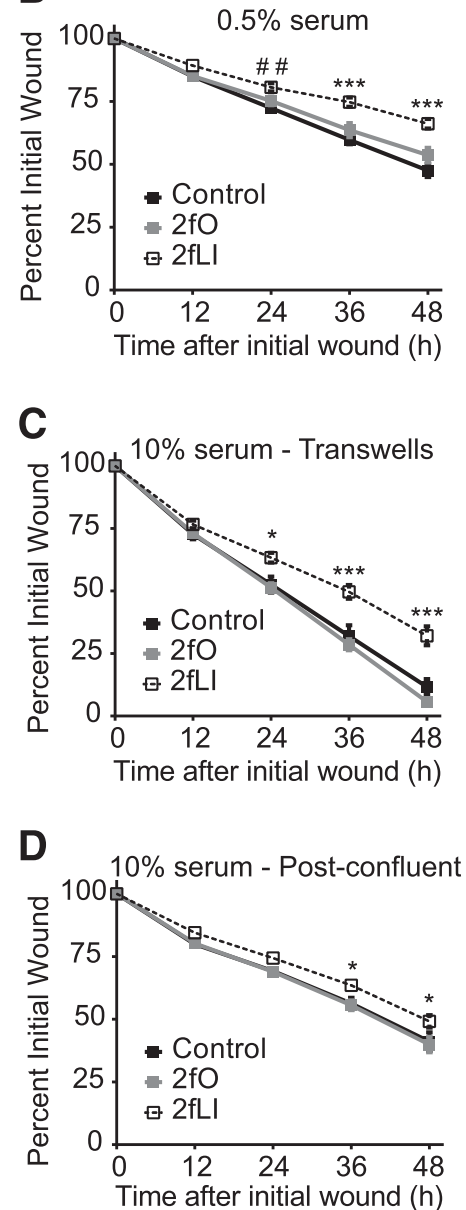

E

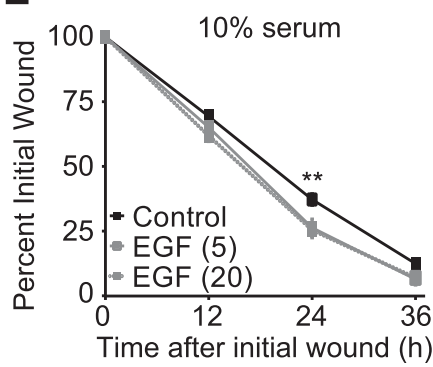

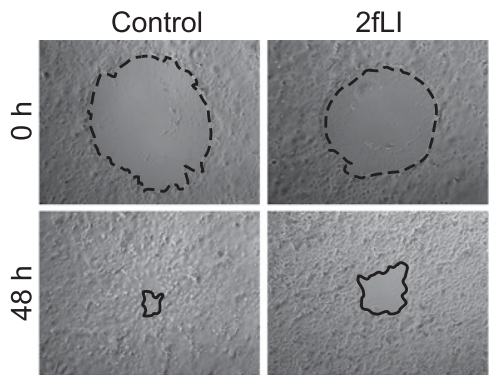
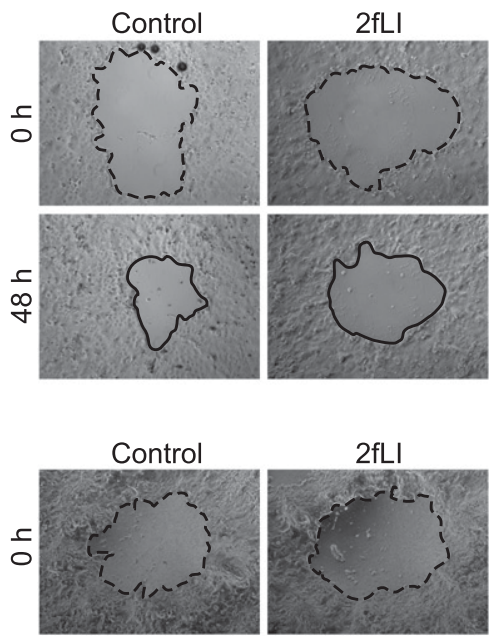

$2 \mathrm{fLI}$
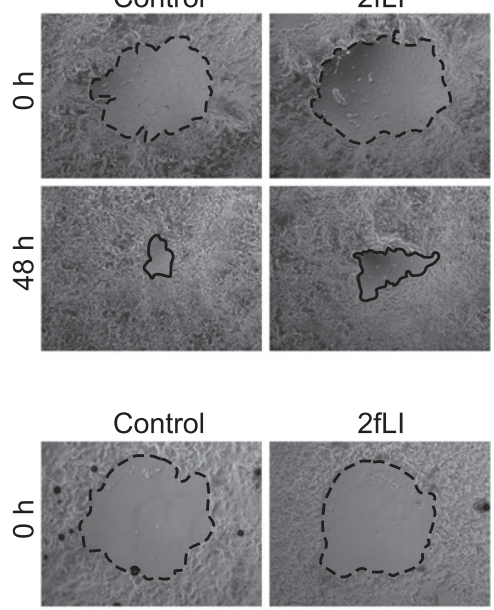

$2 \mathrm{fLI}$
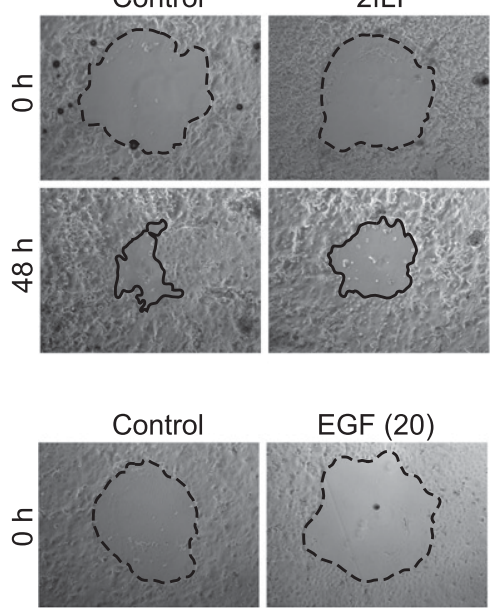

EGF (20)
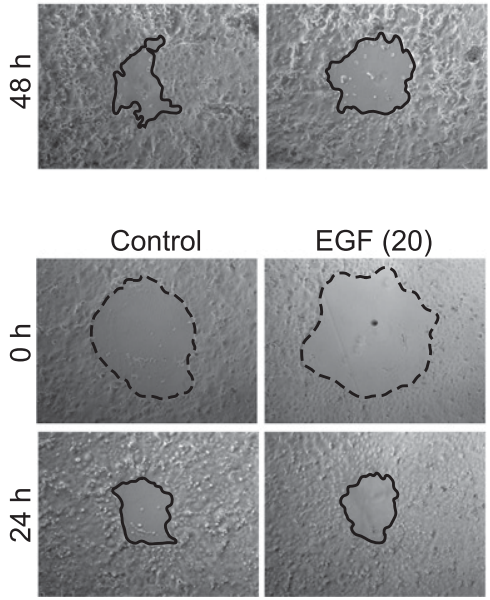

Fig. 1. PAR2 activation inhibited circular wound healing and single cell migration. For circular wound healing, Caco2 cells were grown in several conditions including standard (A, B, and E), polarized (C), and postconfluent (D). $2 \mathrm{fO}$ or $2 \mathrm{fLI}(10 \mu \mathrm{M})$ were added every 12 hours. Representative images are provided for the 48-hour time point, and the dashed line represents the size of the wound at 0 hour. (A and B) After the cells were wounded, media were replaced with fresh media containing either $10 \%$ serum (A, $n=6-9$ ) or $0.5 \%$ serum (B, $n=3-5$ ). (C) Caco2 cells were polarized on Transwell supports $(n=5)$. (D) Caco2 cells were differentiated by growing for 21 days $(n=4)$. (E) As a positive control, following the addition of media containing $10 \%$ serum, EGF (5 and $20 \mathrm{ng} / \mathrm{ml}$ added at 0 and 24 hours) was added to the wounded cells $(n=8)$. Data were analyzed using two-way analysis of variance with Bonferroni's multiple comparisons test. $* P<0.05 ; * * P<0.01 ; * * * P<0.001 ; * * * * P<0.0001$ (significantly different from control and 2fO). \#\#P $<0.01$ (significantly different from control only).

COX-2 Activity Does Not Play a Role in Caco2 Circular Wound Healing. Since the original hypothesis was generated from the previously published observation that PAR2 activation induced COX-2 expression in Caco2 cells (Hirota et al., 2012), we tested the ability of PAR2 to induce
COX-2 in the Caco2 cells used here to ensure the cells were responding as anticipated. Activation of PAR2 using 2fLI was found to induce both concentration- and time-dependent expression of COX-2 (Supplemental Fig. 1, A-D). The activity of COX-2 was also confirmed by measuring the levels of 
A
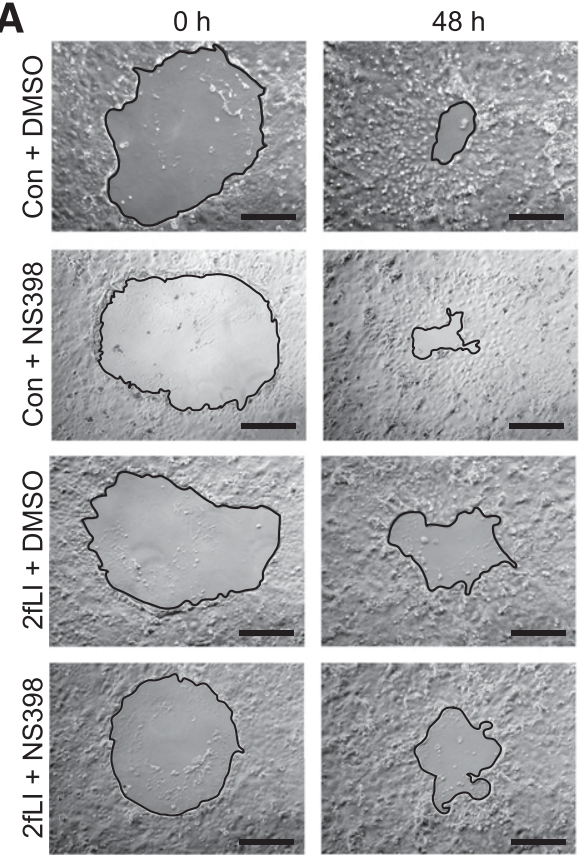

B

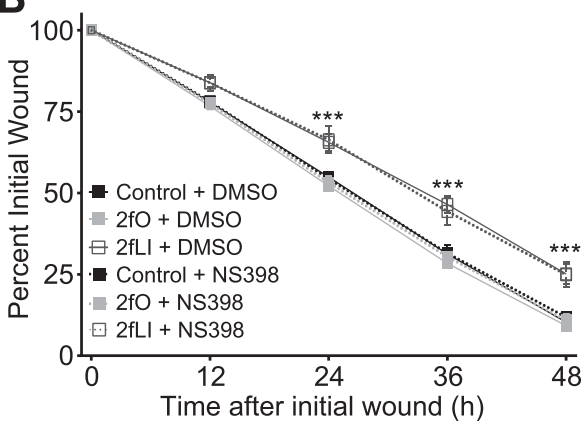

Fig. 2. COX-2 did not play a role in Caco2 wound healing. Caco2 cells were plated and wounded according to the standard protocol, and either DMSO or the COX-2-specific inhibitor NS398 $(10 \mu \mathrm{g} / \mathrm{ml})$ was added to the cells at 0 and 24 hours, in addition to $2 \mathrm{fO}$ or $2 \mathrm{fLI}(10 \mu \mathrm{M})$ every 12 hours. (A) Representative images of the same wound at 0 and 48 hours are shown for select conditions. Scale bar, $500 \mu \mathrm{m}$. (B) Quantification of wound closure ( $n=4$ to 5). Data in (B) were analyzed using two-way analysis of variance with Bonferroni's multiple comparisons test. $* * * P<0.001$ (significantly different from control and 2fO, independent of NS398).

prostaglandin $\mathrm{E}$ metabolite in the supernatant during the time course (Supplemental Fig. 1E). Next, the role of COX-2 during wound healing was analyzed by performing circular wound healing assays in the presence of the COX-2 selective inhibitor, NS-398 (10 $\mu \mathrm{g} / \mathrm{ml}$; Fig. 2). The ability of NS-398 to inhibit COX-2 activity following PAR2 activation was confirmed by measuring prostaglandin $\mathrm{E}$ metabolite levels by enzyme-linked immunosorbent assay (Supplemental Fig. 1E). The inhibition of COX-2 had no effect on circular wound healing in control cells, and importantly, PAR2 activation was still able to inhibit wound closure to the same extent with or without COX-2 inhibition (Fig. 2B). Therefore, the inhibitory effect of PAR2 activation on wound healing in Caco-2 cells is not dependent on COX-2-derived prostanoids.

PAR2 Activation Enhances Proliferation in Confluent Caco2 Cells but Has No Effect at the Wound Edge. With our primary overarching hypothesis disproved, we aimed to characterize the novel observation of PAR2- mediated inhibition of wound healing. First, we studied the effect of PAR2 activation on Caco2 proliferation. Wounded and unwounded cells treated with $2 \mathrm{fO}$ or $2 \mathrm{fLI}(10 \mu \mathrm{M})$ for either 12 or 24 hours were exposed to EdU to identify proliferating cells, and DAPI was used to detect total cell number. At 12 hours, there was a significant increase in proliferation with PAR2 activation in confluent cells that was lost by 24 hours (Fig. 3, left panels). At the wound edge, there was no significant difference in proliferation at 12 or 24 hours with 2fLI treatment compared with $2 \mathrm{fO}$ or control (Fig. 3, right panels). Since the effect of PAR2 activation on Caco 2 proliferation at the wound edge does not explain the inhibition of wound healing, we next investigated the role of PAR2 activation on cell migration.

PAR2 Activation Inhibits Circular Wound Healing through an Effect on Cell Migration. To assess the effect of PAR2 activation on Caco2 sheet migration, wound healing was measured over 48 hours in the absence of proliferation by pretreating cells with MMC ( $5 \mu \mathrm{g} / \mathrm{ml})$. Inhibition of proliferation was confirmed by pretreating cells with DMSO (vehicle control) or MMC, and assessing proliferation using an EdU assay after 48 hours (Fig. 4, A and B). With both DMSO and MMC, wounded Caco2 cells were able to heal, and PAR2 activation significantly inhibited wound closure compared with $2 \mathrm{fO}$ and control (Fig. 4, A and B). These data acquired in the absence of proliferation demonstrated that the PAR2mediated inhibition of wound healing was through an effect on migration. Additionally, live-cell wound healing in Caco2 cells was used to directly measure the distance of wound-edge cell migration by tracking individual cells over 24 hours. Live-cell videos were captured using control cells and cells treated with $2 \mathrm{fO}$ or $2 \mathrm{fLI}$ (10 $\mu \mathrm{M}$; Supplemental Videos 1-3). Cells were tracked from 0 to 24 hours using MTrackJ (Fig. 4C). Cells at the wound edge treated with $2 \mathrm{fLI}$ traveled a significantly shorter distance (87 $\mu \mathrm{m}$ in 24 hours), compared with control cells (139 $\mu \mathrm{m}$ in 24 hours; Fig. 4D). These data further support the hypothesis that PAR2 activation inhibited wound healing by reducing cell migration.

PAR2 Activation Induced Actin Cabling Surrounding the Wound Edge in Caco2 Cells. It was first hypothesized that PAR2 activation inhibited migration in Caco2 cells by affecting lamellipodia formation at the wound edge. Wounded Caco2 cells were fixed after 12 or 24 hours, and phalloidin was used to stain F-actin. Representative images of the entire wound at 24 hours are shown for control (Fig. 5A) and 2fLI-treated (Fig. 5B) wounds. In control cells, there were numerous lamellipodia at the wound edge (Fig. 5A, insets), whereas the wound edge in 2fLI-treated cells had very few lamellipodia but obvious actin cabling (Fig. 5B, insets). Actin dynamics (cabling and lamellipodia formation) in wounds at 12 and 24 hours were blindly quantified, and although there was no significant difference in the actin properties at 12 hours (Fig. 5, C and D), there was a significant increase in actin cabling and a significant decrease in lamellipodia in 2fLItreated wounds compared with control and 2fO-treated wounds at 24 hours (Fig. 5, F and G). These data suggest that alterations in the cytoskeletal response to wounding are inhibited by PAR2 activation.

PAR2 Activation Affected E-Cadherin Internalization but Not ZO-1 Localization in Caco2 Cells at the Wound Edge. It was also hypothesized that PAR2 activation could be inhibiting migration in Caco 2 cells by affecting 

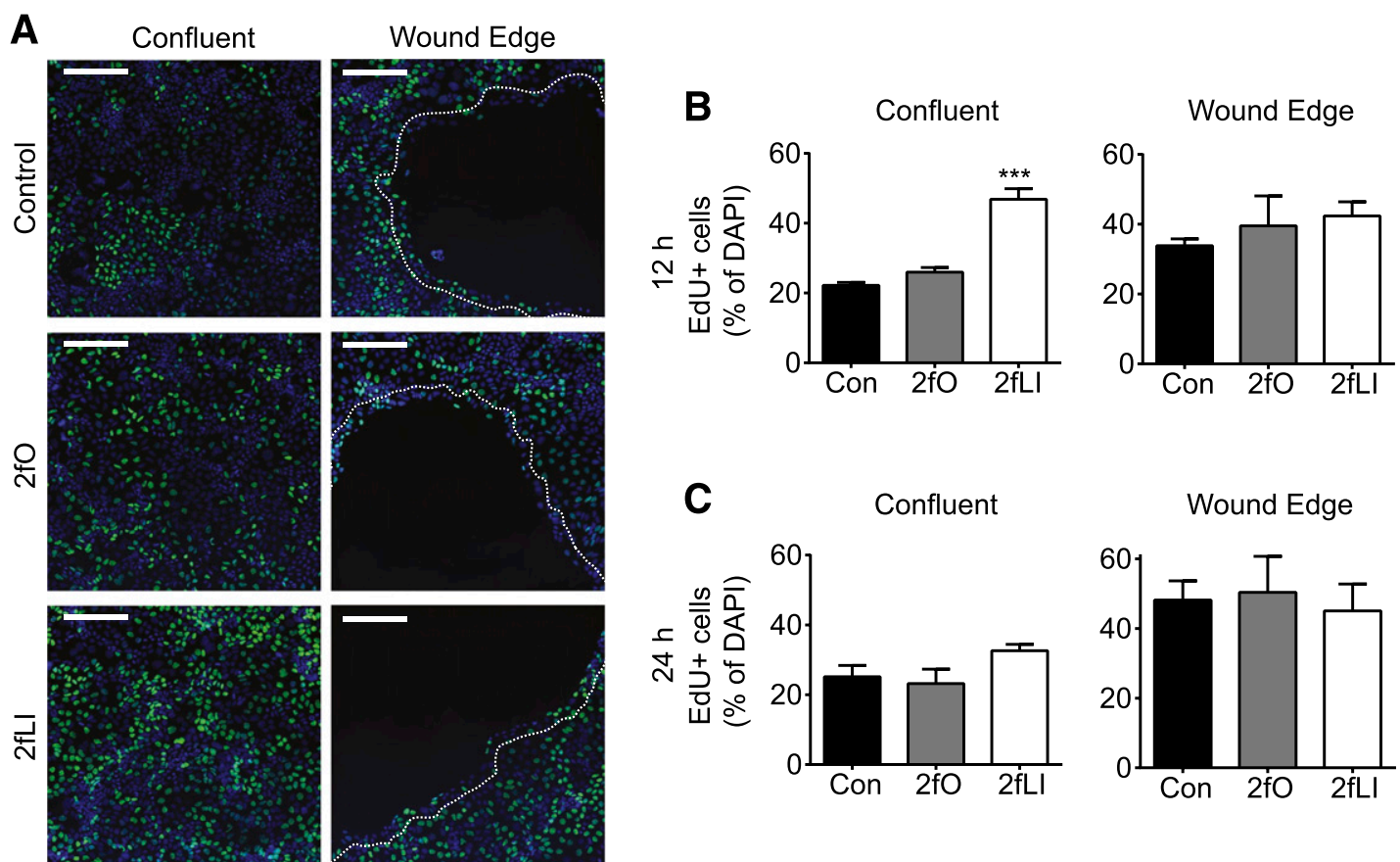

C

Confluent

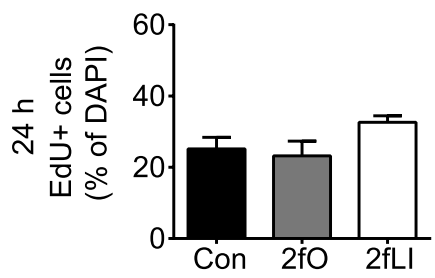

Wound Edge

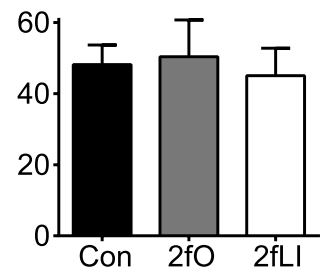

Fig. 3. PAR2 activation enhanced proliferation in confluent cells but had no effect on proliferation at the wound edge. Caco 2 cells were plated and wounded according to the staining protocol and analyzed at 12 and 24 hours. For the 12 -hour time point, cells were wounded, treated with $2 \mathrm{fO}$ or $2 \mathrm{fLI}(10 \mu \mathrm{M})$ at 0 hour, and then returned to the incubator for 12 hours. From 12 to 14 hours, cells were incubated with EdU and then fixed. For the 24-hour time point, cells were wounded, treated with peptides at 0 and 12 hours, and then incubated with EdU from 22 to 24 hours before fixation. Wide-field images were captured, and ImageJ was used to automatically count both DAPI (blue) and EdU+ (green) cells. (A) Representative images from confluent and wound-edge conditions for control, 2fO, and 2fLItreated cells at the 12-hour time point. Scale bar, $200 \mu \mathrm{m}$. (B and C) Quantification (expressed as percentage of EdU-positive cells compared with total DAPIpositive cells) of the confluent and wound-edge data from the 12- and 24-hour time points ( $n=4$ individual experiments with three fields of view/experiment). Data in (B) were analyzed using one-way analysis of variance with Bonferroni's multiple comparisons test. ***P $<0.001$ (compared with control and 2fO).

the loss of cell-cell junctions necessary for epithelial cells to migrate. The adherens junction was analyzed in wounded Caco2 cells, fixed at 12 and 24 hours postwounding, by

A

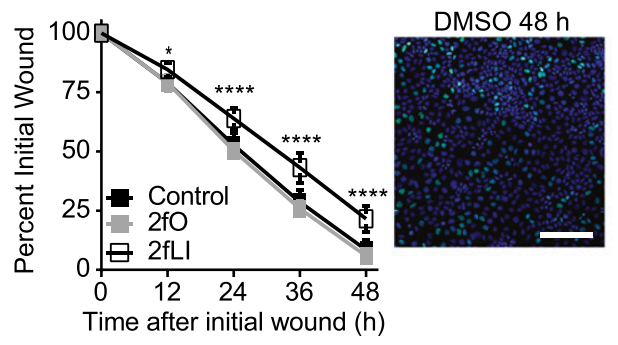

C
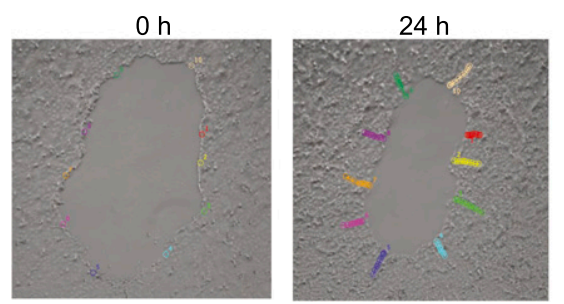

immunofluorescence staining for E-cadherin. In control cells, there was a distinct internalization of E-cadherin in cells surrounding the wound at 24 hours (Fig. 5A, insets) compared

\section{B}

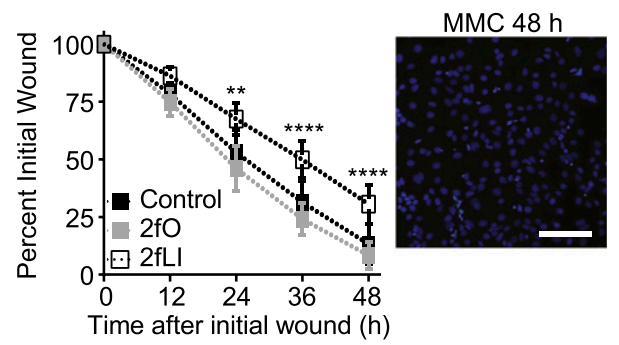

D

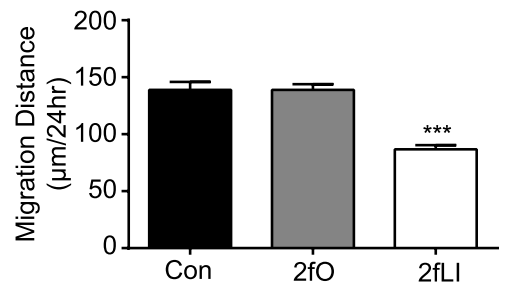

Fig. 4. PAR2 activation inhibited cell migration. (A and B) Caco2 cells were plated and wounded similar to the standard wounding protocol. However, 2 hours prior to wounding, cells were treated with either DMSO (vehicle control, A) or MMC ( $5 \mu \mathrm{g} / \mathrm{ml}$, B) to irreversibly inhibit proliferation ( $n=6$ ). In a similar experiment, cells were plated at the same density and treated for 2 hours with either DMSO or MMC, washed well, and then incubated with EdU from 48 to 50 hours to confirm that proliferation was inhibited for the entirety of the wound healing experiment (right-hand side panels in A and B). Scale bar, $200 \mu \mathrm{m}$. (C and D) Caco2 cells were plated according to the live-cell wound healing protocol. Using the images acquired from the live-cell wound healing experiments, the MTrackJ plugin (ImageJ) was used to track wound-edge cells during the first 24 hours following wounding. (C) An example showing 10 cells around the perimeter of a single wound tracked from 0 to 24 hours. (D) Quantification of the distance that the wound-edge cells traveled, comparing control, $2 \mathrm{fO}$, and $2 \mathrm{fLI}$ $(10 \mu \mathrm{M}) ; n=4$ separate experiments, with three wounds quantified per experiment and 10 cells tracked in each wound. Data were analyzed using two-way analysis of variance with Bonferroni's multiple comparisons test. $* P<0.05$; ** $P<0.01$; *** $P<0.001$; **** $P<0.0001$ (compared with control and 2fO). 
A

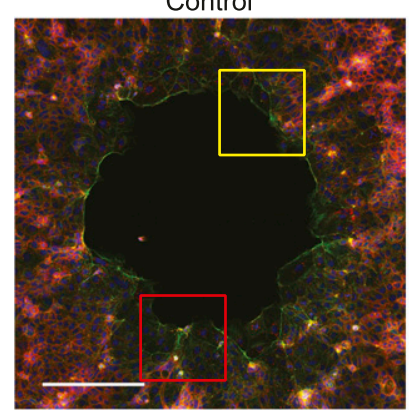

C

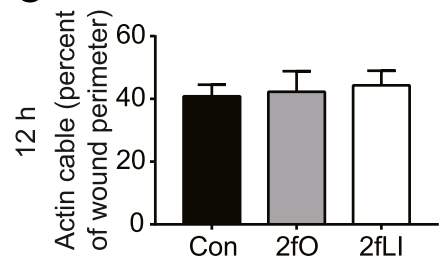

$\mathbf{F}$

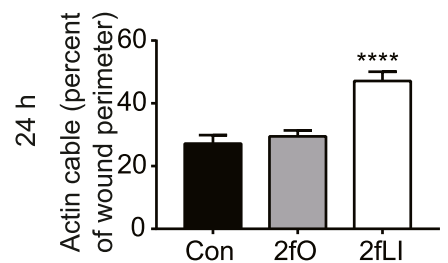

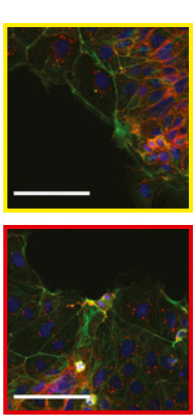

D

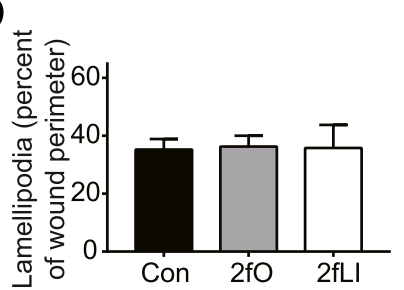

G

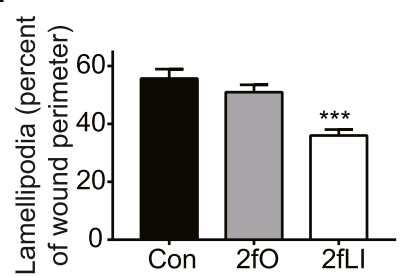

B
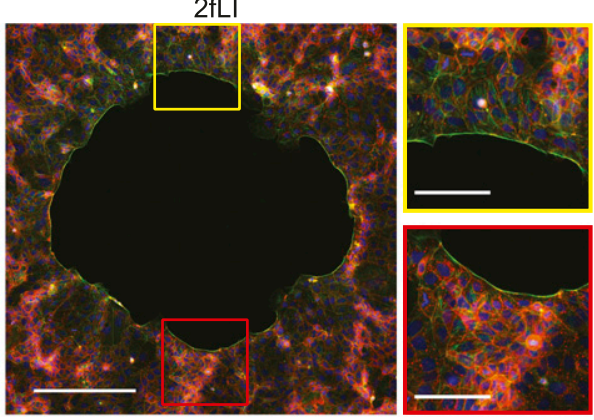

E

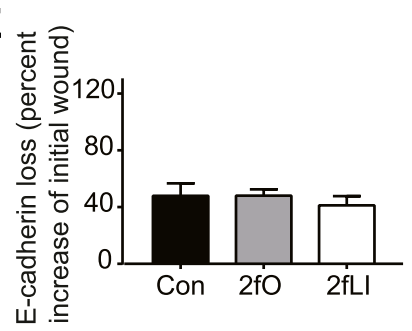

H

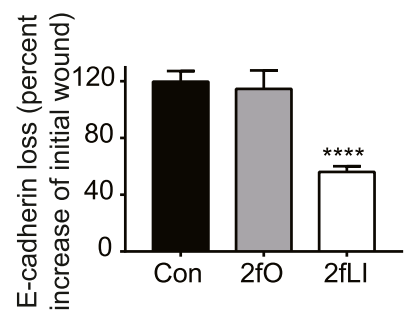

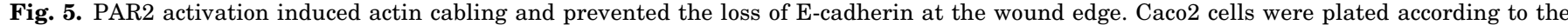

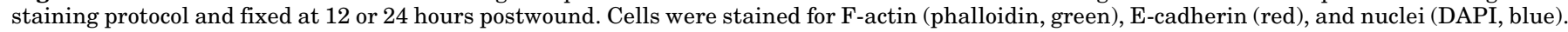

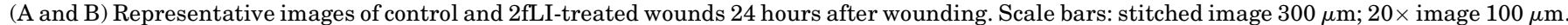

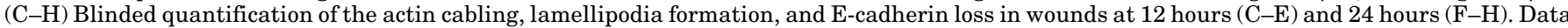

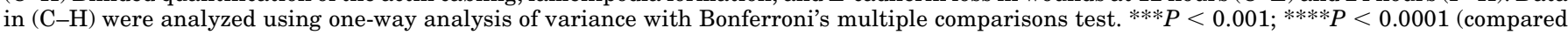
with control and $2 \mathrm{fO}$ ).

with the maintained intercellular E-cadherin expression in cells treated with 2fLI (Fig. 5B, insets). When the loss of intercellular E-cadherin was blindly quantified at 12 hours, there was no significant difference between control, 2fOtreated, and 2fLI-treated wounds (Fig. 5E). However, there was significantly more E-cadherin loss in control and 2fOtreated wounds compared with 2fLI-treated wounds at 24 hours (Fig. 5H). The tight junction protein ZO-1 was also analyzed in wounded Caco 2 cells fixed 24 hours after wounding. Representative images are shown for control (Fig. 6A) and 2fLI-treated wounds (Fig. 6B). Interestingly, ZO-1 expression was even throughout the monolayer up to the edge of the wound, with no differences between control, 2fO-treated (data not shown), and 2fLI-treated wounds. Thus, PAR2 activation is associated with the loss or redistribution of E-cadherin, but not ZO-1, suggesting selective effects on the apical junctional complex in association with the PAR2-mediated inhibition of wound healing in Caco-2 cells.

Wound Healing in Caco2 Cells Was Dependent on Transcription. With a known association between transcriptional activity and cell motility (Olson and Nordheim, 2010), the contribution of transcription to Caco2 wound healing was assessed. When Caco2 cells were treated with actinomycin D $(5 \mu \mathrm{g} / \mathrm{ml})$ during a standard wound healing experiment for 48 hours, the ability of the wounds to heal was almost entirely prevented (control wound healed $14 \%$ at
48 hours) compared with cells treated with DMSO as a control (control wound healed $94 \%$ at 48 hours; Fig. 7). Thus, PAR2 activation did not have a significant effect on the small residual wound healing response that occurs in the absence of transcription, suggesting that any effects of PAR2 on wound healing in Caco-2 cells may be transcriptionally dependent.

PAR2 Activation Induced a Prowound-Healing Transcriptional Program in Caco2. Differential expression lists were generated based on four comparisons: NW-Con versus W-Con, NW-Con versus NW-PAR2, NW-Con versus W-PAR2, and W-Con versus W-PAR2. Only transcripts with a fold change (increase or decrease) of two or greater showing statistical significance $(P<0.05)$ were considered for downstream comparisons. Analysis of changes in gene expression revealed that $113 / 128$ (88\%) of transcripts that were significantly increased with wounding were also increased when PAR2 was activated. Of the overlapping transcripts that were increased, genes of interest are highlighted in Table 1 . Importantly, PAR2 activation did not increase any transcript that was decreased with wounding, or conversely did not decrease any transcript that was increased with wounding (data not shown). To further study the effect of PAR2 activation and wound healing on the transcriptional response of Caco2 cells, the Gene Ontology terms "Cell Migration [0016477]" and "Regulation of Response to Wounding [1903034]" were chosen as gene lists to further characterize. Fold changes were 
A

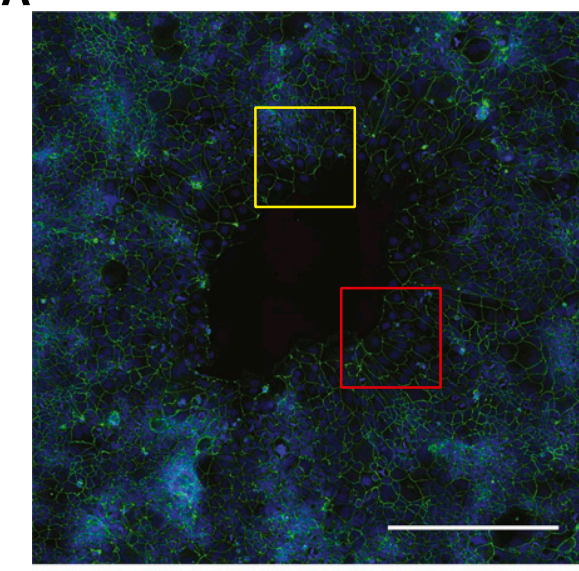

B
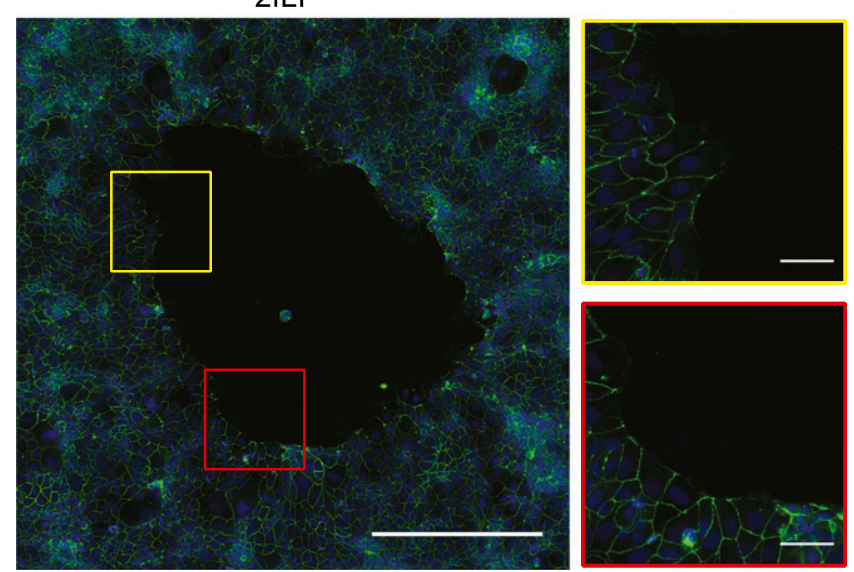

Fig. 6. ZO-1 expression is maintained at the wound edge. Caco 2 cells were plated according to the staining protocol and fixed at 12 or 24 hours postwound. Cells were stained for ZO-1 (green), and nuclei (DAPI, blue). (A and B) Representative images of control and 2fLI-treated wounds 24 hours after wounding. Scale bars: stitched image $400 \mu \mathrm{m} ; 20 \times$ image $50 \mu \mathrm{m}$.

compared and visualized using Microsoft Excel (Supplemental Files 1 and 2, respectively). Paradoxically, many genes that are associated with wounding and migration were increased in the W-PAR2 condition and yet actual wound closure was inhibited with this group in migration assays.

\section{Discussion and Conclusions}

The inflamed intestinal mucosa contains a plethora of proteases that could alter epithelial cell behavior in the inflammatory milieu. PAR2 has long been known to be expressed on human colonic epithelial cells (Bohm et al., 1996) and could be activated by inflammatory proteases. PAR2 activation enhances epithelial proliferation and migration (Darmoul et al., 2004), suggesting that PAR2 activation could mediate enhanced wound healing. Indeed, recent evidence suggests that activation of PAR2 can enhance the healing of scratch wounds in the HT29 colonic epithelial cell line (Jiang et al., 2017). COX-2-derived prostanoids play a role in the resolution of intestinal inflammation (Ajuebor et al., 2000), and COX-2 is induced by PAR2 in the Caco-2 epithelial cell line (Hirota et al., 2012); therefore, PAR2-induced COX-2 expression was studied in Caco2 intestinal epithelial cells to determine if COX-2-derived lipid mediators were required for PAR2-mediated wound healing. We chose the Caco-2 cell line because of our previous experience using this line to study epithelial responses to PAR2 activation, and because Caco-2 monolayers are a commonly used model for studies of wound healing in the context of inflammatory stimuli (Chiriac et al., 2017). Our data from this study confirm that Caco-2 cells express PAR2 (Supplemental Fig. 2). Activation of PAR2 was achieved using the selective activating peptide, 2fLI. While some small peptide agonists of PAR2 exhibit biased agonism that may favor a noncanonical signaling pathway (Hollenberg et al., 2014), 2fLI activates signaling pathways similar to those activated by enzymatic cleavage of the receptor (McGuire et al., 2004).

The most significant observation from our study was that, in contrast to the original hypothesis, PAR2 activation in Caco2 intestinal epithelial cells significantly inhibited circular wound healing. This novel observation was made in cells that were serum starved overnight ( $0 \% \mathrm{FBS})$, and then allowed to heal in the presence of either full serum (10\% FBS) or low serum $(0.5 \% \mathrm{FBS})$, as well as with polarized and differentiated Caco2 cells. Interestingly, although PAR2 activation has been shown to transactivate EGFR in Caco2 cells (Hirota et al., 2012), wound healing was enhanced with EGF treatment compared with control, as has been previously demonstrated (Dise et al., 2008). Our findings suggest that the primary PAR2 signaling pathway resulting in the inhibition of wound healing is not through EGFR transactivation. In addition, although we showed that PAR2 activation induced COX-2 expression in Caco-2 cells (Hirota et al., 2012), PAR2 effects on wound healing occurred independently of COX-2 activity. Furthermore, COX-2 inhibition on its own did not affect the baseline rate of wound healing, likely due to the fact that Caco2 cells are low constitutive expressers of COX-2 as we have shown (Hirota et al., 2012).

The individual components of wound healing (proliferation and migration) were investigated to further characterize the inhibition of wound healing by PAR2 activation. Decreased proliferation following PAR2 exposure may have explained the inhibitory effect of PAR2 on wound healing. However, proliferation at the wound edge did not differ between groups, and a significant increase in proliferation was detected with PAR2 activation in confluent cells. These data corroborate the previously described PAR2-mediated increases in proliferation (Darmoul et al., 2004), and suggest that altered proliferation does not play a role in the effect of PAR2 activation on Caco2 wound healing. To further assess this, cell proliferation was irreversibly inhibited using MMC. Under these conditions, Caco2 cells were still able to heal and PAR2 activation was still able to significantly inhibit wound healing. These observations fit the go-or-grow hypothesis, which suggests that proliferation and migration are temporally, mutually exclusive phenotypes in some cancer models (Xie et al., 2014). If PAR2 signaling was overwhelming the cells with a proproliferative signal, it might have been preventing the cells from developing the necessary migratory phenotype required to move.

Cell migration is dependent on changes in cytoskeletal dynamics; therefore, we investigated the effect of PAR2 activation on actin distribution and cell morphology in wounded Caco-2 monolayers. At 24 hours there were significantly fewer lamellipodia and significantly more actin cabling 

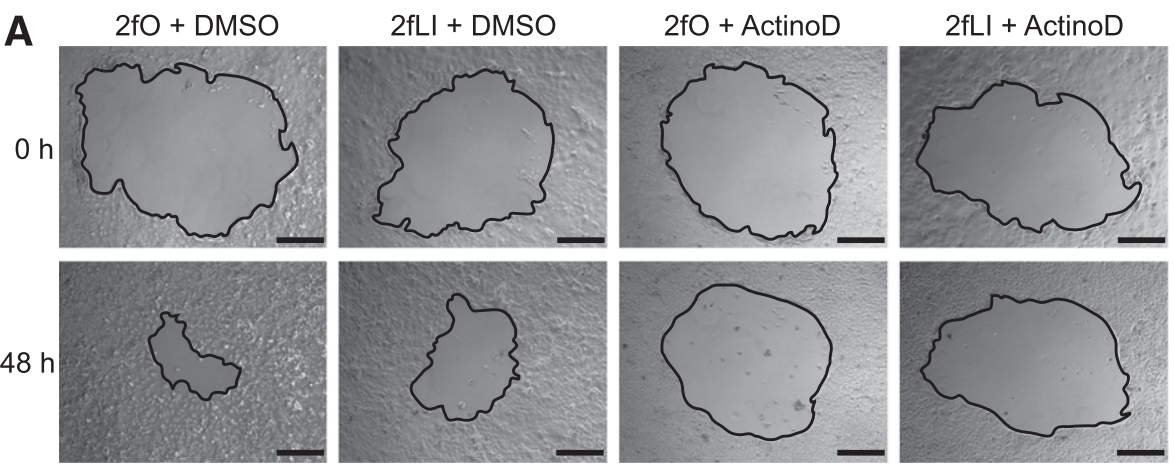

\section{B}

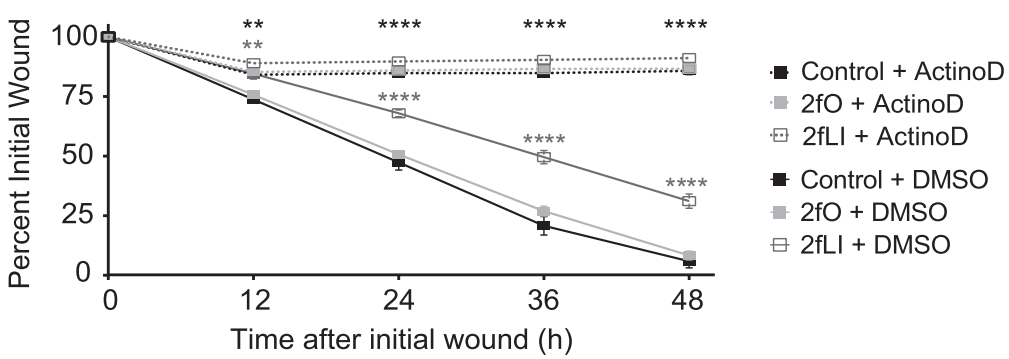

Fig. 7. Wound healing in Caco2 cells is dependent on transcription. Caco2 cells were plated and wounded according to the standard protocol, and then treated with either actinomycin $\mathrm{D}(5 \mu \mathrm{g} / \mathrm{ml})$ or an equivalent volume of DMSO (1:200) prior to the addition of $2 \mathrm{fO}$ or $2 \mathrm{fLI}(10 \mu \mathrm{M}$ at 0 hour). (A) Representative images of the same wound at 0 and 48 hours with either $2 \mathrm{fO}$ or $2 \mathrm{fLI}$ and DMSO or actinomycin D $(n=4)$. Scale bar, $400 \mu \mathrm{m}$. (B) Quantification of wound closure. Data in (B) were analyzed using two-way analysis of variance with Bonferroni's multiple comparisons test. ${ }^{* *} P<0.01 ;{ }^{* * * *} P<0.0001$ (gray: 2fLI + DMSO significantly different than $2 \mathrm{fO}$ and control + DMSO; black: actinomycin D significantly different than DMSO). at the wound edge following PAR2 activation. Importantly, actin regulation during epithelial wound healing depends on the size of the wound. Small epithelial wounds (with fewer than 10 cells along the wound circumference) do not require protrusions from wound-edge cells but instead heal through purse-string wound closure, which involves the contraction of an actin cable that is transmitted through adherens junctions of cells at the wound edge (Russo et al., 2005). Conversely, larger wounds, such as those that we induced in our Caco-2 monolayers, require filipodia and lamellipodia formation from leader cells at the wound edge. Importantly, leader cells can only form protrusions when the actin cable at the wound edge is no longer present (Reffay et al., 2014). Our data suggest that PAR2 activation may prevent the formation of leader cells by inducing the formation of actin cables, and that this may be a mechanism whereby PAR2 activation blocks wound healing in this cell line.
It is well described that E-cadherin redistribution is required for epithelial cell migration (Peglion et al., 2014; Haeger et al., 2015); therefore, we investigated whether PAR2 activation could prevent the internalization of E-cadherin at the wound edge. Cells were fixed during the wound healing process, stained for E-cadherin, and changes in the area of E-cadherin staining near the wound edge were quantified. Because distribution of junctional proteins is more important functionally than actual amounts, we did not quantify E-cadherin (for example, by western blot). At 24 hours, there was considerable loss of E-cadherin in cells surrounding wounds in untreated, control monolayers. However, E-cadherin expression was maintained at the wound edge in cells treated with the PAR2-activating peptide. This was not a global effect on junctional proteins, since the distribution of the tight junction protein, ZO-1, was not altered

TABLE 1

Genes of interest increased with wounding in control cells, and increased with PAR2 activation in unwounded cells

\begin{tabular}{|c|c|c|c|c|}
\hline Gene Symbol & $\begin{array}{l}\text { W-Con Fold Change } \\
\text { Compared with NW-Con }\end{array}$ & $\begin{array}{l}\text { NW-PAR 2-Fold Change } \\
\text { Compared with NW-Con }\end{array}$ & $\begin{array}{l}\text { W-PAR 2-Fold Change } \\
\text { Compared with NW-Con }\end{array}$ & $\begin{array}{l}\text { W-PAR 2-Fold Change } \\
\text { Compared with W-Con }\end{array}$ \\
\hline PTGS2 & 2.9 & 3.7 & 6.0 & 2.0 \\
\hline F2RL1 & 2.4 & 3.7 & 6.0 & 2.5 \\
\hline CLDN2 & 2.7 & 8.7 & N.D. & 3.5 \\
\hline ADAMTS9 & 2.2 & 2.2 & N.D. & N.D. \\
\hline MMP1 & 2.2 & 3.8 & 3.0 & 1.4 \\
\hline MMP10 & 3.2 & 6.2 & 5.3 & 1.6 \\
\hline ANXA1 & 4.6 & 4.8 & 1.6 & 1.7 \\
\hline AREG & 3.7 & 4.0 & 1.8 & 2.0 \\
\hline EREG & 2.2 & 2.6 & 1.5 & 1.7 \\
\hline FOS & 5.1 & 6.6 & 1.5 & 1.9 \\
\hline FOSB & 12.2 & 3.7 & 4.8 & 1.4 \\
\hline FOSL1 & 6.4 & 9.4 & 1.9 & 2.7 \\
\hline JUN & 2.5 & 4.1 & 6.9 & 2.8 \\
\hline JUNB & 4.1 & 5.0 & 1.9 & 2.4 \\
\hline CCL20 & 5.3 & 8.6 & 12.9 & 4.0 \\
\hline CXCR4 & 4.8 & 4.8 & 12.4 & 2.5 \\
\hline CXCL8 & 27.2 & 5.5 & 7.7 & 1.6 \\
\hline
\end{tabular}

N.D., not detected. 
by PAR2 activation. The endocytosis of E-cadherin is necessary for proper actomyosin regulation during wound closure (Hunter et al., 2015). Thus, taken together, the data suggest PAR2 activation results in changes in actin dynamics and E-cadherin distribution that suppress the normal wound healing response. However, we recognize that conflicting data exist, particularly the observation that E-cadherin expression and relocalization to the apical junctional complex are required for collective cell migration in Caco-2 cells under some conditions (Hwang et al., 2012), highlighting the complex nature of E-cadherin, cell-cell junction regulation, and actin dynamics during sheet migration, and suggesting that further studies will be required to uncover the cellular mechanisms responsible for the regulation of wound healing in Caco-2 cells.

Wound healing in epithelial monolayers is primarily transcriptionally dependent, as we confirmed in our studies using actinomycin $\mathrm{D}$. The small residual wound healing response observed in actinomycin D-treated monolayers was not further inhibited by PAR2 activation, suggesting that the inhibitory effect of PAR2 on wound healing is also dependent on transcription. RNA sequencing was chosen as an optimal method to continue to investigate the PAR2-mediated inhibition of Caco2 wound healing, since it has been shown that cytoskeletal dynamics are intricately related to genome activity (Olson and Nordheim, 2010).

Triplicates of four experimental conditions were sequenced: NW-Con, W-Con, NW-PAR2, and W-PAR2. The comparisons first analyzed in this project were NW-Con versus W-Con and NW-Con versus NW-PAR2, which were prioritized to compare the transcriptome induced by wounding to the transcriptome induced following PAR2 activation. Interestingly, $88 \%$ of the transcripts that were increased ( $>2$-fold) when the control cells were wounded were also increased with PAR2 activation. Included in this overlap were genes that change their expression at the wound edge during sheet migration, including claudin-2 (Ikari et al., 2011), CXCR4 (Ghosh et al., 2012), as well as c-FOS, FOSB, and FOSL1 (Renaud et al., 2014). In relation to these genes of interest, it has also been shown that ERK1/2 is persistently activated at the leading edge during sheet migration (Block et al., 2010). Importantly, when ERK1/2 is universally activated across the entire monolayer, rather than specifically at the wound edge, there is no organized sheet migration and cells do not move in a coordinated direction (Chapnick and Liu, 2014). Therefore, expression and activation of specific proteins at the wound edge likely play a large role in communicating the direction of movement that is needed. Since PAR2 activation canonically signals through ERK1/2, and increases the expression of other wound-edge-associated factors, it is possible that activation of PAR2 is creating a universal increase in genes that are required solely at the wound edge. This could explain how PAR2 activation inhibits Caco2 wound healing even in the presence of the prowound healing transcriptional profile.

Additional genes of interest that were upregulated with both wounding and PAR2 activation, and have previously been shown to modulate wound healing, include regulators of extracellular matrix components (ADAMTS9, MMP1, and MMP10) (Rohani and Parks, 2015), annexin A1 (Leoni et al., 2013, 2015), EGFR ligands (amphiregulin and epiregulin) (Yamaoka et al., 2011), as well as chemokines and chemokine receptors (CCL20, CXCR4, and IL-8) (Wilson et al., 1999; Vongsa et al., 2009; Ghosh et al., 2012). Due to their strong association with epithelial wound healing in the literature, these select genes of interest are important candidates for potential future studies. To further investigate wound healing factors from the RNA sequencing results, we used gene lists for specific Gene Ontology terms to narrow our focus. With both "Regulation of Response to Wounding" and "Cell Migration," many of the genes induced or repressed by wounding and/or PAR2 activation remained at similar levels under wounded PAR2-activated conditions. While at first glance these RNA sequencing data are contradictory to the observation that PAR2-activated and wounded $\mathrm{CaCo} 2$ monolayers do not heal as quickly as controls, it does emphasize just how complex the wound healing process is. It is tempting to speculate that PAR2 activation is indeed inducing a specific type of prowound healing response, but it is not the response required by Caco2 cells needed to heal a large circular wound. Indeed, we have shown previously that PAR2 is an important modulator of the apoptotic response under inflammatory conditions (Iablokov et al., 2014), and several mediators of apoptosis normally supressed by PAR2 activation such as BCL2L11, BIRC3, and IKBKB are seen to be changed by PAR2 activation; however, these transcript changes are lost when activated cells are also wounded (Supplemental Files). This is supported by the presence of the actin cable and E-cadherin expression at the wound edge, which are required to heal small circular wounds. Taken together with the increased proliferation in Caco2 cells distant from the wound edge, and the increased expression of many woundedge-associated genes, it is likely that the wound healing signals and PAR2 activation signals may be working at cross purposes, resulting in uncoordinated movement and proliferation that lead to cell jamming (Sadati et al., 2013; Garcia et al., 2015).

In conclusion, contrary to observations in other intestinal epithelial cell lines, PAR2 activation inhibits, rather than enhances, wound healing in Caco-2 cells, likely due to the net effect of inducing the expression of some, but inhibiting the expression of other, genes that regulate the complex pathways associated with wound healing and cell migration. Our findings provide a cautionary tale for the use of cancer cell lines in the study of these repair pathways. The advent of primary cell organoid cultures may provide a better option for future studies of the factors that regulate wound healing and repair in the inflamed gut.

\section{Authorship Contributions}

Participated in research design: Fernando, Beck, MacNaughton. Conducted experiments: Fernando, Gordon.

Performed data analysis: Fernando, Gordon.

Wrote or contributed to the writing of the manuscript: Fernando, Gordon, MacNaughton.

\section{References}

Ajuebor MN, Singh A, and Wallace JL (2000) Cyclooxygenase-2-derived prostaglandin $\mathrm{D}_{2}$ is an early anti-inflammatory signal in experimental colitis. Am J Physiol Gastrointest Liver Physiol 279:G238-G244.

Beck PL, Rosenberg IM, Xavier RJ, Koh T, Wong JF, and Podolsky DK (2003) Transforming growth factor- $\beta$ mediates intestinal healing and susceptibility to injury in vitro and in vivo through epithelial cells. Am J Pathol 162:597-608.

Block ER, Tolino MA, Lozano JS, Lathrop KL, Sullenberger RS, Mazie AR and Klarlund JK (2010) Free edges in epithelial cell sheets stimulate epidermal growth factor receptor signaling. Mol Biol Cell 21:2172-2181.

Bohm SK, Kong W, Bromme D, Smeekens SP, Anderson DC, Connolly A, Kahn M, Nelken NA, Coughlin SR, Payan DG, et al. (1996) Molecular cloning, expression and potential functions of the human proteinase-activated receptor-2. Biochem $J$ 314:1009-1016. 
Chapnick DA and Liu X (2014) Leader cell positioning drives wound-directed collective migration in TGF $\beta$-stimulated epithelial sheets. Mol Biol Cell 25:1586-1593.

Charrier L, Yan Y, Driss A, Laboisse CL, Sitaraman SV, and Merlin D (2005) ADAM15 inhibits wound healing in human intestinal epithelial cell monolayers. Am J Physiol Gastrointest Liver Physiol 288:G346-G353.

Chiriac MT, Buchen B, Wandersee A, Hundorfean G, Gunther C, Bourjau Y, Doyle SE, Frey B, Ekici AB, Buttner C, et al. (2017) Activation of epithelial signal transducer and activator of transcription 1 by interleukin 28 controls mucosal healing in mice with colitis and is increased in mucosa of patients with inflammatory bowel disease. Gastroenterol 153:123-138.e8.

Darmoul D, Gratio V, Devaud H, and Laburthe M (2004) Protease-activated receptor 2 in colon cancer: trypsin-induced MAPK phosphorylation and cell proliferation are mediated by epidermal growth factor receptor transactivation. J Biol Chem $\mathbf{2 7 9}$ : 20927-20934

Dise RS, Frey MR, Whitehead RH, and Polk DB (2008) Epidermal growth factor stimulates Rac activation through Src and phosphatidylinositol 3-kinase to promote colonic epithelial cell migration. Am J Physiol Gastrointest Liver Physiol $\mathbf{2 9 4}$ G276-G285.

Garcia S, Hannezo E, Elgeti J, Joanny JF, Silberzan P, and Gov NS (2015) Physics of active jamming during collective cellular motion in a monolayer. Proc Natl Acad Sci USA 112:15314-15319.

Ge L, Shenoy SK, Lefkowitz RJ, and DeFea K (2004) Constitutive protease-activated receptor-2-mediated migration of MDA MB-231 breast cancer cells requires both $\beta$-arrestin-1 and -2. $J$ Biol Chem 279:55419-55424.

Ghosh MC, Makena PS, Gorantla V, Sinclair SE, and Waters CM (2012) CXCR4 regulates migration of lung alveolar epithelial cells through activation of Rac1 and matrix metalloproteinase-2. Am J Physiol Lung Cell Mol Physiol 302:L846-L856.

Haeger A, Wolf K, Zegers MM, and Friedl P (2015) Collective cell migration: guidance principles and hierarchies. Trends Cell Biol 25:556-566.

Halter F, Tarnawski AS, Schmassmann A, and Peskar BM (2001) Cyclooxygenase 2-implications on maintenance of gastric mucosal integrity and ulcer healing: controversial issues and perspectives. Gut 49:443-453.

Hirota CL, Moreau F, Iablokov V, Dicay M, Renaux B, Hollenberg MD, and MacNaughton WK (2012) Epidermal growth factor receptor transactivation is required for proteinase-activated receptor-2-induced COX-2 expression in in testinal epithelial cells. Am J Physiol Gastrointest Liver Physiol 303:G111-G119.

Hollenberg MD, Mihara K, Polley D, Suen JY, Han A, Fairlie DP, and Ramachandran $\mathrm{R}$ (2014) Biased signalling and proteinase-activated receptors (PARs): targeting inflammatory disease. $B r$ J Pharmacol 171:1180-1194.

Hollenberg MD, Renaux B, Hyun E, Houle S, Vergnolle N, Saifeddine M, and Ramachandran R (2008) Derivatized 2-furoyl-LIGRLO-amide, a versatile and selective probe for proteinase-activated receptor 2 : binding and visualization. $J$ Pharmacol Exp Ther 326:453-462.

Houliston RA, Keogh RJ, Sugden D, Dudhia J, Carter TD, and Wheeler-Jones CP (2002) Protease-activated receptors upregulate cyclooxygenase-2 expression in human endothelial cells. Thromb Haemost 88:321-328.

Huang RYJ, Guilford P, and Thiery JP (2012) Early events in cell adhesion and polarity during epithelial-mesenchymal transition. J Cell Sci 125:4417-4422.

Hunter MV, Lee DM, Harris TJ, and Fernandez-Gonzalez R (2015) Polarized E-cadherin endocytosis directs actomyosin remodeling during embryonic wound repair. J Cell Biol 210:801-816.

Hwang S, Zimmerman NP, Agle KA, Turner JR, Kumar SN, and Dwinell MB (2012) E-cadherin is critical for collective sheet migration and is regulated by the chemokine CXCL12 protein during restitution. J Biol Chem 287:22227-22240.

Iablokov V, Hirota CL, Peplowski MA, Ramachandran R, Mihara K, Hollenberg MD, and MacNaughton WK (2014) Proteinase-activated receptor 2 (PAR2) decreases apoptosis in colonic epithelial cells. J Biol Chem 289:34366-34377.

Iizuka $\mathrm{M}$ and Konno S (2011) Wound healing of intestinal epithelial cells. World $J$ Gastroenterol 17:2161-2171.

Ikari A, Takiguchi A, Atomi K, Sato T, and Sugatani J (2011) Decrease in claudin-2 expression enhances cell migration in renal epithelial Madin-Darby canine kidney cells. J Cell Physiol 226:1471-1478.

Jiang Y, Yau MK, Kok WM, Lim J, Wu KC, Liu L, Hill TA, Suen JY, and Fairlie DP (2017) Biased signaling by agonists of protease activated receptor 2. ACS Chem Biol 12:1217-1226.

Kaplan GG and Ng SC (2017) Understanding and preventing the global increase of inflammatory bowel disease. Gastroenterol 152:313-321.e2.

Kawao N, Nagataki M, Nagasawa K, Kubo S, Cushing K, Wada T, Sekiguchi F, Ichida S, Hollenberg MD, MacNaughton WK, et al. (2005) Signal transduction for proteinase-activated receptor-2-triggered prostaglandin $\mathrm{E}_{2}$ formation in human lung epithelial cells. J Pharmacol Exp Ther 315:576-589.

Kuhn KA, Manieri NA, Liu TC, and Stappenbeck TS (2014) IL-6 stimulates intestinal epithelial proliferation and repair after injury. PLoS One 9:e114195.

Lacy ER (1988) Epithelial restitution in the gastrointestinal tract. J Clin Gastroenterol 10 (Suppl 1):S72-S77.

Leoni G, Alam A, Neumann PA, Lambeth JD, Cheng G, McCoy J, Hilgarth RS, Kundu K, Murthy N, Kusters D, et al. (2013) Annexin A1, formyl peptide receptor, and NOX1 orchestrate epithelial repair. J Clin Invest 123:443-454

Leoni G, Neumann PA, Kamaly N, Quiros M, Nishio H, Jones HR, Sumagin R, Hilgarth RS, Alam A, Fredman G, et al. (2015) Annexin A1-containing extracellular vesicles and polymeric nanoparticles promote epithelial wound repair. J Clin Invest 125:1215-1227.

Li YJ, Kanaji N, Wang XQ, Sato T, Nakanishi M, Kim M, Michalski J, Nelson AJ, Farid M, Basma H, et al. (2015) Prostaglandin $\mathrm{E}_{2}$ switches from a stimulator to an inhibitor of cell migration after epithelial-to-mesenchymal transition. Prostaglandins Other Lipid Mediat 116-117:1-9.

Maeda S, Ohno K, Uchida K, Igarashi H, Goto-Koshino Y, Fujino Y, and Tsujimoto H (2014) Intestinal protease-activated receptor-2 and fecal serine protease activity are increased in canine inflammatory bowel disease and may contribute to intestinal cytokine expression. J Vet Med Sci 76:1119-1127.

Manieri NA, Drylewicz MR, Miyoshi H, and Stappenbeck TS (2012) Igf2bp1 is required for full induction of Ptgs 2 mRNA in colonic mesenchymal stem cells in mice. Gastroenterol 143:110-121.e10.

McGuire JJ, Saifeddine M, Triggle CR, Sun K, and Hollenberg MD (2004) 2-furoylLIGRLO-amide: a potent and selective proteinase-activated receptor 2 agonist. $J$ Pharmacol Exp Ther 309:1124-1131.

Miyoshi H, VanDussen KL, Malvin NP, Ryu SH, Wang Y, Sonnek NM, Lai CW, and Stappenbeck TS (2017) Prostaglandin E2 promotes intestinal repair through an adaptive cellular response of the epithelium. EMBO $J$ 36:5-24.

Mize GJ, Wang W, and Takayama TK (2008) Prostate-specific kallikreins-2 and -4 enhance the proliferation of DU-145 prostate cancer cells through proteaseactivated receptors-1 and -2. Mol Cancer Res 6:1043-1051.

Mizuno H, Sakamoto C, Matsuda K, Wada K, Uchida T, Noguchi H, Akamatsu T, and Kasuga M (1997) Induction of cyclooxygenase 2 in gastric mucosal lesions and its inhibition by the specific antagonist delays healing in mice. Gastroenterology 112:387-397.

Morris DR, Ding Y, Ricks TK, Gullapalli A, Wolfe BL, and Trejo J (2006) Proteaseactivated receptor-2 is essential for factor VIIa and Xa-induced signaling, migration, and invasion of breast cancer cells. Cancer Res 66:307-314.

Olson EN and Nordheim A (2010) Linking actin dynamics and gene transcription to drive cellular motile functions. Nat Rev Mol Cell Biol 11:353-365.

Pastorelli L, De Salvo C, Mercado JR, Vecchi M, and Pizarro TT (2013) Central role of the gut epithelial barrier in the pathogenesis of chronic intestinal inflammation: lessons learned from animal models and human genetics. Front Immunol 4:280.

Peglion F, Llense F, and Etienne-Manneville S (2014) Adherens junction treadmilling during collective migration. Nat Cell Biol 16:639-651.

Pineton de Chambrun G, Blanc P, and Peyrin-Biroulet L (2016) Current evidence supporting mucosal healing and deep remission as important treatment goals for inflammatory bowel disease. Expert Rev Gastroenterol Hepatol 10:915-927.

Raithel M, Winterkamp S, Pacurar A, Ulrich P, Hochberger J, and Hahn EG (2001) Release of mast cell tryptase from human colorectal mucosa in inflammatory bowel disease. Scand J Gastroenterol 36:174-179.

Reffay M, Parrini MC, Cochet-Escartin O, Ladoux B, Buguin A, Coscoy S, Amblard F Camonis J, and Silberzan P (2014) Interplay of RhoA and mechanical forces in collective cell migration driven by leader cells. Nat Cell Biol 16:217-223.

Renaud SJ, Kubota K, Rumi MA, and Soares MJ (2014) The FOS transcription factor family differentially controls trophoblast migration and invasion. J Biol Chem 289: 5025-5039.

Rohani MG and Parks WC (2015) Matrix remodeling by MMPs during wound repair. Matrix Biol 44-46:113-121.

Russo JM, Florian P, Shen L, Graham WV, Tretiakova MS, Gitter AH, Mrsny RJ, and Turner JR (2005) Distinct temporal-spatial roles for rho kinase and myosin light chain kinase in epithelial purse-string wound closure. Gastroenterology 128: 987-1001.

Sadati M, Taheri Qazvini N, Krishnan R, Park CY, and Fredberg JJ (2013) Collective migration and cell jamming. Differentiation 86:121-125.

Savla U, Appel HJ, Sporn PH, and Waters CM (2001) Prostaglandin $\mathrm{E}_{2}$ regulates wound closure in airway epithelium. Am J Physiol Lung Cell Mol Physiol 280 L421-L431.

Schmassmann A, Peskar BM, Stettler C, Netzer P, Stroff T, Flogerzi B, and Halter F (1998) Effects of inhibition of prostaglandin endoperoxide synthase-2 in chronic gastro-intestinal ulcer models in rats. $\mathrm{Br} J$ Pharmacol 123:795-804.

Shafran I, Maurer W, and Thomas FB (1977) Prostaglandins and Crohn's disease. $N$ Engl J Med 296:694-695.

Shi K, Queiroz KC, Stap J, Richel DJ, and Spek CA (2013) Protease-activated receptor-2 induces migration of pancreatic cancer cells in an extracellular ATPdependent manner. J Thromb Haemost 11:1892-1902.

Singer II, Kawka DW, Schloemann S, Tessner T, Riehl T, and Stenson WF (1998) Cyclooxygenase 2 is induced in colonic epithelial cells in inflammatory bowel disease. Gastroenterology 115:297-306.

Vongsa RA, Zimmerman NP, and Dwinell MB (2009) CCR6 regulation of the actin cytoskeleton orchestrates human beta defensin-2- and CCL20-mediated restitution of colonic epithelial cells. J Biol Chem 284:10034-10045.

Wallace JL and Devchand PR (2005) Emerging roles for cyclooxygenase-2 in gastrointestinal mucosal defense. Br J Pharmacol 145:275-282.

Wilson AJ, Byron K, and Gibson PR (1999) Interleukin-8 stimulates the migration of human colonic epithelial cells in vitro. Clin Sci (Lond) 97:385-390.

Xie Q, Mittal S, and Berens ME (2014) Targeting adaptive glioblastoma: an overview of proliferation and invasion. Neuro-oncol 16:1575-1584.

Yamaoka T, Frey MR, Dise RS, Bernard JK, and Polk DB (2011) Specific epidermal growth factor receptor autophosphorylation sites promote mouse colon epithelia cell chemotaxis and restitution. Am J Physiol Gastrointest Liver Physiol 301: G368-G376.

Zeeh F, Witte D, Gadeken T, Rauch BH, Grage-Griebenow E, Leinung N, Fromm SJ, Stolting S, Mihara K, Kaufmann R, et al. (2016) Proteinase-activated receptor 2 promotes TGF- $\beta$-dependent cell motility in pancreatic cancer cells by sustaining expression of the TGF- $\beta$ type I receptor ALK5. Oncotarget 7:41095-41109.

Zhou B, Zhou H, Ling S, Guo D, Yan Y, Zhou F, and Wu Y (2011) Activation of PAR2 or/and TLR4 promotes SW620 cell proliferation and migration via phosphorylation of ERK1/2. Oncol Rep 25:503-511.

Address correspondence to: Wallace K. MacNaughton, Department of Physiology and Pharmacology, University of Calgary, 3330 Hospital Dr. NW, Calgary, AB T2N 4N1, Canada. E-mail: wmacnaug@ucalgary.ca 